\title{
Charge-Transfer Fluorescence and Room-Temperature Phosphorescence from a Bisamide-Based Derivative
}

\author{
Chengjian Li ${ }^{1,2}$, Chaozheng Zhuo ${ }^{1}$, Jingwei Sun ${ }^{1, *(\mathbb{D})}$ and Mi Ouyang ${ }^{2, *}$ \\ 1 Department of Materials Chemistry, Huzhou University, Xueshi Road No.1, Huzhou 313000, China; \\ chengiianli1996@foxmail.com (C.L.); zcz17857685232@163.com (C.Z.) \\ 2 College of Chemical Engineering, Zhejiang University of Technology, Chaowang Road No.18, \\ Hangzhou 310014, China \\ * Correspondence: 02488@zjhu.edu.cn (J.S.); ouyang@zjut.edu.cn(M.O.)
}

check for

updates

Citation: Li, C.; Zhuo, C.; Sun, J.; Ouyang, M. Charge-Transfer Fluorescence and Room-Temperature Phosphorescence from a BisamideBased Derivative. Crystals 2021, 11, 1370. https://doi.org/10.3390/ cryst 11111370

Academic Editors: Pierre-Henri Lanoë, Frédérique Loiseau and Damien Jouvenot

Received: 13 October 2021

Accepted: 27 October 2021

Published: 11 November 2021

Publisher's Note: MDPI stays neutral with regard to jurisdictional claims in published maps and institutional affiliations.

Copyright: (c) 2021 by the authors. Licensee MDPI, Basel, Switzerland. This article is an open access article distributed under the terms and conditions of the Creative Commons Attribution (CC BY) license (https:// creativecommons.org/licenses/by/ $4.0 /)$.

\begin{abstract}
The development of organic luminescent materials with bimodal emissions of both fluorescence and room-temperature phosphorescent (RTP) remains a challenge. The investigation of the relationship between fluorescence and RTP performance is especially rare. In this work, we obtained an organic luminescent molecule, 1,4-phenylenebis((9H-carbazol-9-yl)methanone) (PBCM), which exhibits bimodal emissions of cyan fluorescence and yellow RTP in its crystalline state through adopting an electron donor-acceptor-donor (D-A-D) structure. The charge-transfer (CT) effects in the bimodal luminescent properties of PBCM, as well as the single-crystal structures and thermal properties, were investigated. It was found that the CT effect in the singlet states effectively reduces the $\Delta \mathrm{E}_{\mathrm{st}}$ and promotes the ISC processes, resulting in an efficient phosphorescence of PBCM at room temperature. In addition, many strong intermolecular interactions are formed between the donor and acceptor parts of adjacent molecules, leading to the rigid configurations and compact packing of molecules in crystals, which was also confirmed to facilitate the efficient bimodal emissions of PBCM.
\end{abstract}

Keywords: charge-transfer; photoluminescence; molecular interactions

\section{Introduction}

Photoluminescence, including fluorescence and phosphorescence, is one of the most active research fields in science and technology today [1-4]. Luminescent materials, especially the organic ones with efficient performance in the condensed states, have attracted significant attention in recent years. Currently, the applications of luminescent materials in biological imaging, display and OLEDs or LCDs, security systems, and other functional materials are greatly developing [5-7]. However, organic phosphorescent materials have not achieved the same level of development as fluorescent ones because of the low efficiencies of the triplet state phosphorescence, especially at room temperature [8-10]. However, phosphorescent materials have significantly broader opportunities compared with fluorescent materials because of the comparatively slower decay rates of the triplet excited states. For example, in cellular hypoxia imaging, phosphorescent materials exclude the effects of the cellular auto-fluorescence background [11]. In addition, phosphorescent materials with a high yield of the triplet excited state, whose numbers are three times larger than that of singlet excitons, are desired components in electroluminescent devices requiring high efficiencies [12,13]. Therefore, in the recent past, organic phosphorescent materials, particularly room-temperature phosphorescent (RTP) organic solids, have gradually become the focus of attention. Additionally, more and more ultra-long phosphorescent materials, which display luminous radiation with lifetimes of over $100 \mathrm{~ms}$, were reported [14].

Phosphorescence arises from the forbidden radiation (triplet to singlet) of the excited triplet states. In general, $\mathrm{T}_{1}$ states have lower energy than $\mathrm{S}_{1}$ states of organic molecules, which results in the further redshift of the phosphorescence emission band compared with the fluorescence bands of the molecules [15]. Thus, phosphorescence is generally 
observed in the long-wavelength region because of their relatively low energy bands in emission relative to fluorescence. In addition, the triplet excited state of organic molecules is prone to be quenched through non-radiative relaxation in the process of overheating and collision and is sensitive to the presence of $\mathrm{O}_{2}$ molecules, which result in triplet-triplet quenching processes [16]. Hence, the development of organic phosphorescent compounds has long been limited to harsh conditions, such as low temperatures and inert environments. Nonetheless, in 1984, Love et al. published the first article on RTP of polynuclear aromatic hydrocarbons (PAHs) inside the cyclodextrin cavity [17]. Since then, more and more researchers have entered the field. Now, RTP can be induced by a variety of means, such as the introduction of heavy atoms, metal frames and host-guest systems, the formation of single crystals, and embedding into a polymer matrix [18-22].

Although great progress has been made in the past few years, the development of organic luminescent materials with bimodal emissions of both fluorescence and RTP remains a challenge. The investigation of the relationship between fluorescence and RTP performance is especially rare. In this work, we obtained an organic luminescent molecule, 1,4-phenylenebis((9H-carbazol-9-yl)methanone) (PBCM), through adopting an electron donor-acceptor-donor (D-A-D) structure, as shown in Scheme 1, which exhibits bimodal emissions of cyan fluorescence and yellow RTP in its crystalline state. The charge-transfer (CT) effects in the bimodal luminescent properties of PBCM, as well as the single-crystal structures and thermal properties, were investigated. The introduction of the D-A-D structure was found to promote the CT effect and modulate the energy levels to the lower CT state, resulting in efficient inter-system crossing (ISC) processes. In addition, many strong intermolecular interactions are formed between the donor and acceptor parts of adjacent molecules, leading to rigid configurations and compact packing of molecules in crystals. Both the above findings were confirmed to facilitate the efficient bimodal emissions of PBCM.
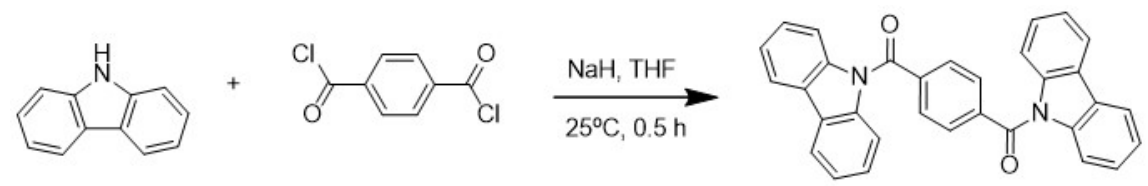

PBCM

Scheme 1. Synthetic route to PBCM.

\section{Materials and Methods}

All chemicals were purchased from commercial sources and used without further purification, including terephthaloyl dichloride, carbazole, sodium hydride $(\mathrm{NaH})$, tetrahydrofuran (THF), anhydrous magnesium sulfate, etc. All other solvents are commercially available and were used as received unless otherwise stated.

${ }^{1} \mathrm{H}$ NMR and ${ }^{13} \mathrm{C}$ NMR were obtained using an Avance III nuclear magnetic resonance spectrometer from Bruker, Switzerland, with tetramethylsilane (TMS) as the internal standard and deuterated chloroform $\left(\mathrm{CDCl}_{3}\right)$ as the solvent. Low-resolution mass spectrometry (MS) data were collected on a ThermoFisher ITQ1100 mass spectrometer and bombarded with an ESI source. Fourier transform infrared spectroscopy (FTIR) was recorded on a Nicolet 6700 (Thermo Fisher Nicolet, USA). The ultraviolet-visible absorption spectrum (UV-Vis) was tested on a Shimadzu UV-2600 UV-visible spectrophotometer in Japan. The photoluminescence (PL) spectra were tested on a SENS-9000 steady-state fluorescence spectrometer from Gilden Photonics, UK. The PL quantum efficiencies were obtained using a C11347-11 absolute quantum efficiency meter from Japan's Hamamatsu Company. The lifetimes of the luminogens were tested on a Hitachi F7000 transient fluorescence spectrometer. X-ray crystallographic intensity data were collected using an Xcalibur, Eos, Gemini Ultra CCD diffractometer equipped with a graphite monochromated Enhance (Mo) X-ray source $(\lambda=0.71073 \AA)$. Powder X-ray diffraction (XRD) was performed on an $X^{\prime}$ Pert Pro from Panaco, the Netherlands, using $\mathrm{Cu}-\mathrm{K} \alpha$ at $40 \mathrm{kV}$ and $40 \mathrm{~mA}$. 
Synthesis of 1,4-phenylenebis((9H-carbazol-9-yl)methanone) (PBCM): In an ice water bath, terephthaloyl dichloride $(0.406 \mathrm{~g}, 2 \mathrm{mmol})$ and carbazole $(0.668 \mathrm{~g}, 4.2 \mathrm{mmol})$ were dissolved in $50 \mathrm{~mL}$ of THF solution in a flat bottom flask. Then, sodium hydride $(0.5 \mathrm{~g}$, $20 \mathrm{mmol}$ ) was slowly added, and the mixture was stirred at $0^{\circ} \mathrm{C}$ for $10 \mathrm{~min}$. After removing the ice water bath, the mixture was stirred at room temperature for another $20 \mathrm{~min}$. A concentrated crude product was obtained successively by suction filtration, washing with dichloromethane (DCM), and rotary evaporation of the filtrate. Finally, the crude product was further purified using column chromatography to produce $0.62 \mathrm{~g}$ of white powder with a yield of $66.7 \% .{ }^{1} \mathrm{H}$ NMR $\left(400 \mathrm{MHz}, \mathrm{CDCl}_{3}\right): \delta(\mathrm{ppm}) 8.04-8.02(\mathrm{~m}, 4 \mathrm{H}), 7.89(\mathrm{~s}$, $4 \mathrm{H}), 7.61-7.59(\mathrm{~m}, 4 \mathrm{H}), 7.43-7.36(\mathrm{~m}, 8 \mathrm{H}) .{ }^{13} \mathrm{C} \mathrm{NMR}\left(100 \mathrm{MHz}, \mathrm{CDCl}_{3}\right): \delta(\mathrm{ppm}) 168.47$, $139.12,138.89,129.54,126.99,126.30,123.93,120.04,115.86$. FTIR C-H $3042 \mathrm{~cm}^{-1}(\mathrm{w}), \mathrm{C}=\mathrm{O}$ $1673 \mathrm{~cm}^{-1}$ (s), $\mathrm{C}=\mathrm{C} 1443 \mathrm{~cm}^{-1}$ (s), C-N $1328 \mathrm{~cm}^{-1}$ (s). MS m/z: calculated for $\mathrm{C}_{32} \mathrm{H}_{20} \mathrm{~N}_{2} \mathrm{O}_{2}$, 464.15; found $[\mathrm{M}+\mathrm{H}]^{+}, 465.2$.

Colorless block crystals of PBCM were obtained by slow evaporation from a mixed solution of DMSO and THF. Crystallographic data: $\mathrm{C}_{32} \mathrm{H}_{20} \mathrm{~N}_{2} \mathrm{O}_{2}, \mathrm{M}=464.50 \mathrm{~g} / \mathrm{mol}$, monoclinic, $\mathrm{a}=15.2226(9) \AA, \mathrm{b}=5.0117(3) \AA, \mathrm{c}=15.0606(10) \AA ; \alpha=90^{\circ}, \beta=109.002(2)^{\circ}$, $\gamma=90^{\circ} \mathrm{V}=1086.38(12) \AA^{3}, \mathrm{~T}=100 \mathrm{~K}, \mathrm{R}$ (int) $=0.0517$, space group $\mathrm{P} 121 / \mathrm{c} 1$, Dcalc $=1.420 \mathrm{~g} \cdot \mathrm{cm}^{-3}, \mathrm{~S}=1.021, \mathrm{Z}=2$. The final $\mathrm{R}$ indices were $\mathrm{R} 1=0.0530, \mathrm{wR} 2=0.1688$ $(\mathrm{I}>2 \sigma(\mathrm{I}))$, and $\mathrm{CCDC}=2,111,683$.

\section{Results and Discussion}

\subsection{Charge-Transfer Fluorescence of PBCM}

The optical properties of $\mathrm{PBCM}$ were investigated in pure THF and THF/water mixed solutions. As shown in Figure 1a, PBCM exhibited a maximum absorption peak at about $282 \mathrm{~nm}$, which can be attributed to the (n, $\left.\pi^{*}\right)$ transition and a shoulder band around $315 \mathrm{~nm}$, which may be due to the $\left(\pi, \pi^{*}\right)$ transition of the conjugated molecule. In the mixed THF/water solutions, PBCM displayed absorption at a similar position as that in THF. However, when the water fraction $\left(f_{\mathrm{w}}\right)$ was increased to 90 and $99 \%$, the intensity was markedly enhanced, with the tail rising up and extending into the long-wavelength region. These results illustrate that $\mathrm{PBCM}$ molecules aggregate into nanoparticles in the THF/water mixed solutions with $f_{\mathrm{w}} \geq 90 \%$, which leads to the Mie scattering effect. As for the PL $\left(\lambda_{\text {ex }}=310 \mathrm{~nm}\right)$ in Figure 1b, some fine vibronic peaks at 343 and $358 \mathrm{~nm}$ were observed in pure THF solution, which originated from the localized emission (LE) of PBCM in the mono-molecular state. However, when $f_{\mathrm{w}}$ reached $90 \%$, a broad band arose around $476 \mathrm{~nm}$, which was even further red-shifted to $516 \mathrm{~nm}$ when $f_{\mathrm{w}}=99 \%$, which could be assigned to the charge-transfer (CT) emission. CT emission is usually observed in polar conditions for a large number of donor-acceptor substituted aromatic compounds. Compared with the LE emission, CT fluorescence is strongly red-shifted and weakened, and the position of the CT band is found to be highly solvent dependent. This new emission band red-shifts along with the increase of solvent polarity resulting from the increase in $f_{\mathrm{w}}$, which also confirms its CT nature. These results indicate that the generation of the CT fluorescence in the long-wavelength region is induced by intermolecular charge transfer resulting from the aggregation of PBCM molecules [23].

Notably, the intensity ratio between the LE and CT emission of the PBCM suspension depended on the excitation wavelength $\left(\lambda_{\mathrm{e}}\right)$, as shown in Figure 2 . When excited at $250 \mathrm{~nm}$, no CT peak was observed from PBCM in the water/THF mixture $\left(f_{\mathrm{w}}=90 \%\right)$. When $\lambda_{\mathrm{e}}$ exceeds $270 \mathrm{~nm}$, the CT band appeared and was gradually strengthened, along with the increase in the LE peak. When $\lambda_{\mathrm{e}}$ approached $310 \mathrm{~nm}$, the CT band was continuously enhanced; however, the LE emission was weakened, leading to the increased ratio of CT fluorescence from PBCM aggregates. The LE and CT bands originated from the single molecules and aggregates, respectively. The variation of the LE/CT bands intensities might be attributed to the different absorption spectra of the single molecules and aggregates. The strongest intensity of the emission band was observed when the excitation wavelength reached the maximum of the corresponding absorption band. These results reveal that 
the LE emission from PBCM molecules requires higher-energy excitation, and when $\lambda_{\mathrm{e}}$ becomes larger, the CT emission from PBCM aggregates, which only requires lower-energy excitation, becomes stronger.

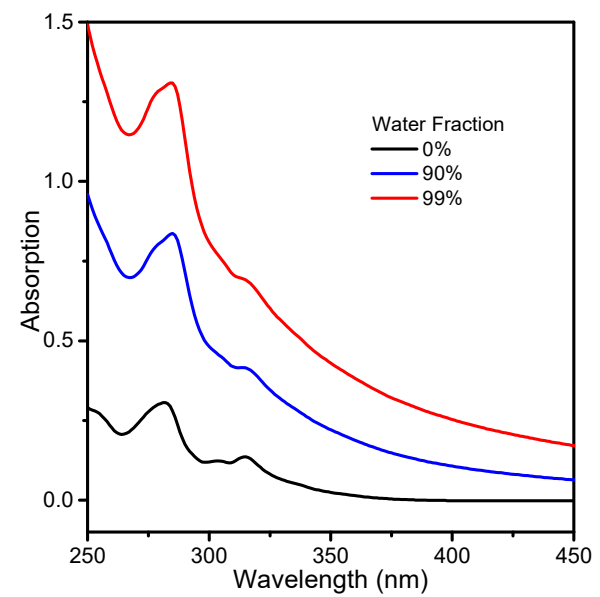

(a)

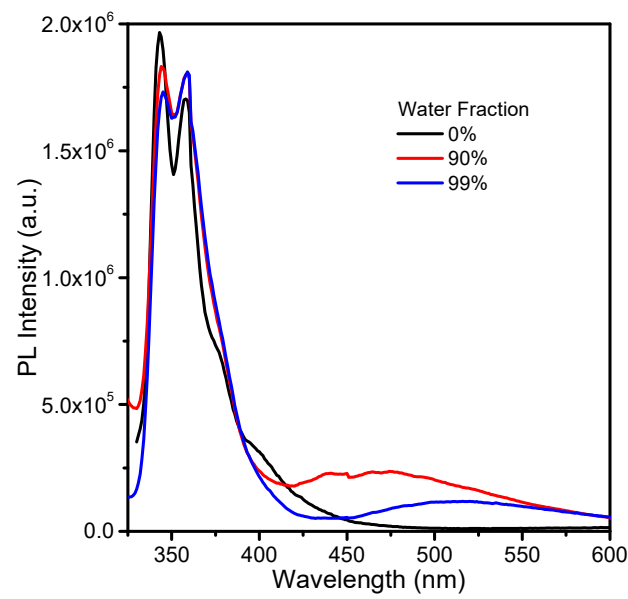

(b)

Figure 1. (a) Absorption and (b) PL spectra of PBCM in THF/water mixed solutions with different fractions of water.

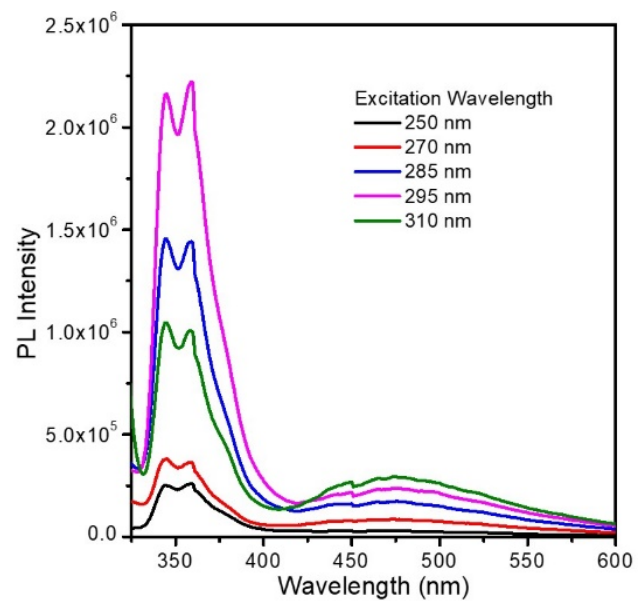

Figure 2. PL spectra of PBCM in water/THF mixture $\left(f_{\mathrm{w}}=90 \%\right)$ for different excitation wavelengths.

\subsection{Bimodal Luminescence from PBCM Crystals}

When illuminated under a UV light at $365 \mathrm{~nm}$, the PBCM solids displayed a cyan emission, which, however, transformed to yellow upon the removal of the UV light. The photoluminescence quantum yields reached $6.6 \%\left(\lambda_{\mathrm{ex}}=350 \mathrm{~nm}\right)$. Notably, the yellow emission lasted for a few seconds in the dark at room temperature, indicating its room temperature phosphorescent (RTP) nature. Figure 3 presents the prompt and delayed PL spectra of PBCM crystals at room temperature. A wide prompt PL band was observed with a maximum peak at $481 \mathrm{~nm}$, which was attributed to the CT fluorescence due to the similar wavelength to those of PBCM aggregates in the suspension. In addition, two shoulders were observed at 529 and $574 \mathrm{~nm}$, which were identified as the phosphorescent emission because of the similar wavelength as those peaks of the delayed PL (531 and $575 \mathrm{~nm}$ ). These results confirm that PBCM crystals exhibit bimodal emissions of CT fluorescence and RTP, leading to a cyan color under UV light and a transformation to yellow in the absence of UV excitation. 


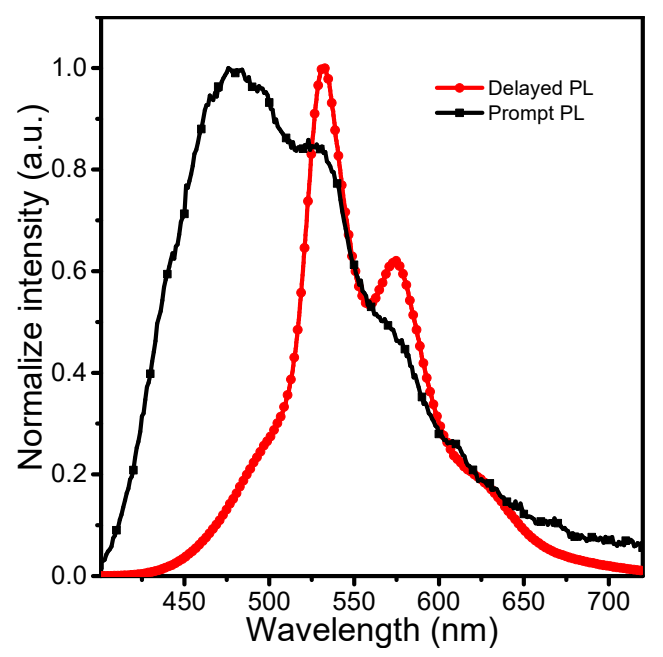

Figure 3. Prompt and delayed PL of PBCM crystals.

The lifetime of the bimodal luminescence was investigated, as shown in Figure 4. The fluorescence at $481 \mathrm{~nm}$ decayed in a single exponential profile, resulting in a lifetime of $2.04 \mathrm{~ns}$. This indicates that the fluorescence of PBCM crystals stems from one single excited state, i.e., CT exciton. However, the lifetime of the RTP at $530 \mathrm{~nm}$ reached $139.78 \mathrm{~ms}$ in the air. This led to the long afterglow of PBCM crystals upon removing the UV light. The significantly red-shifted CT fluorescence of $\mathrm{PBCM}$ promoted its remarkably long afterglow, as the CT state could act as a mediating state for the ISC process owing to the substantially smaller $\Delta \mathrm{E}_{\mathrm{st}}$ for the CT state than for the LE state of PBCM [24].

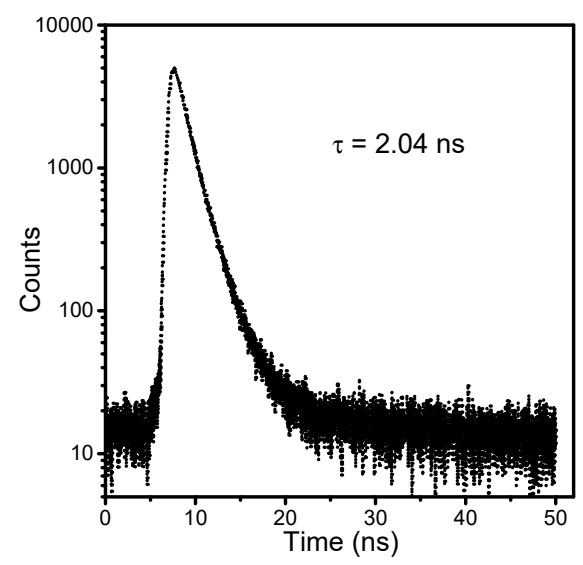

(a)

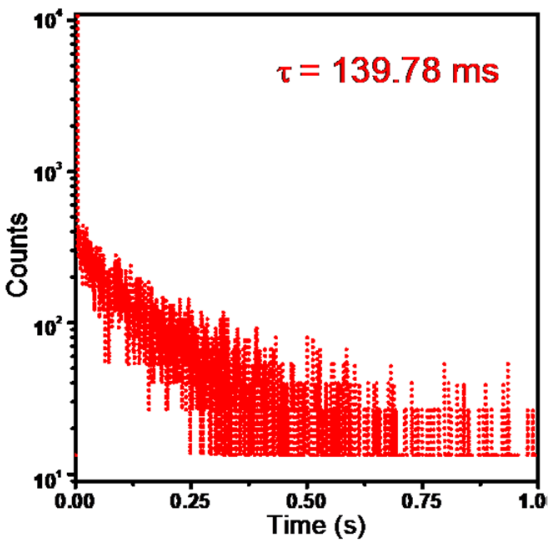

(b)

Figure 4. (a) Fluorescent decay profile of PBCM; (b) phosphorescence decay profile of PBCM.

\subsection{Single-Crystal X-ray Structure of PBCM}

Single crystals of $\mathrm{PBCM}$ suitable for X-ray crystallographic analysis were obtained via the slow evaporation of a mixture of DMSO and THF solution at room temperature. As shown in Figure 5, the simulated PXRD from the single crystal exhibited multiple sharp diffraction peaks at the same positions as those of the PBCM powder crystals. Thus, the structure result of the obtained single crystal could be adopted to explain the in-depth mechanism of the optical properties of PBCM. As shown in Figure 6a, the dihedral angles between the ring of benzene and its neighboring two carbazole-9-carbonyl planes are $+26.64^{\circ}$ and $-26.64^{\circ}$. These results indicate that PBCM adopts a twisted conformation to facilitate the CT fluorescence in solids. The lone pair orbital of nitrogen of charge donor carbazole is almost orthogonal to the $\pi$-orbitals of the benzene ring in the twisted geometry, which stabilizes the charge transfer state of PBCM. As shown in Figure 6b, the crystal structure of PBCM consists of four molecules in a unit cell. It belongs to a monoclinic 
system with the space group P $121 / \mathrm{c} 1$ ( $\mathrm{a}=15.2226(9) \AA, \mathrm{b}=5.0117(3) \AA$, c $=15.0606(10) \AA$; $\left.\alpha=90^{\circ}, \beta=109.002(2)^{\circ}, \gamma=90^{\circ}\right)$. Four molecules are tightly connected by abundant C-H ... O hydrogen bonds, with distances of 2.340 and $2.609 \AA$ 年etween the carbonyl group in one molecule and the hydrogen in neighboring molecules. The existence of rich and powerful intermolecular interactions in the crystal is sufficient to provide a rigid environment to prohibit intramolecular vibration and rotation, which result in the strong fluorescence of PBCM in solids [25]. In addition, PBCM shows a dense crystal packing with a large density of $1.420 \mathrm{~g} \cdot \mathrm{cm}^{-3}$, which further protects materials from oxygen quenching by reducing the contact area. Thus, a strong RTP was also observed in PBCM crystals.

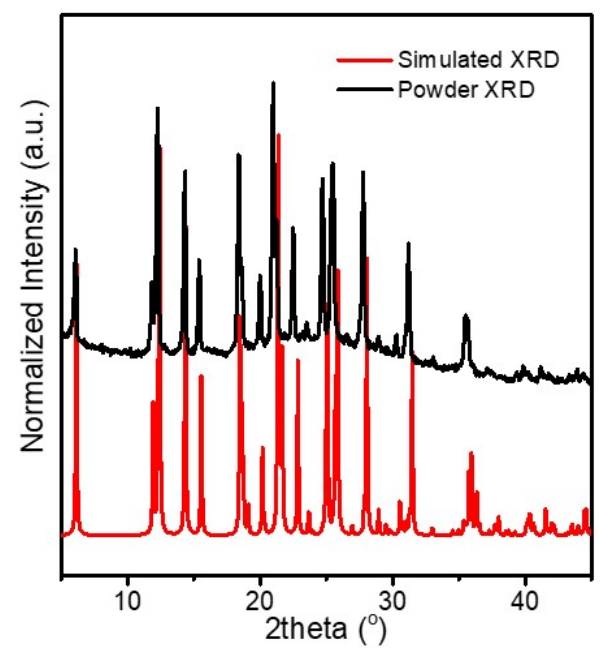

Figure 5. Powder XRD and simulated XRD from the single-crystal of PBCM.

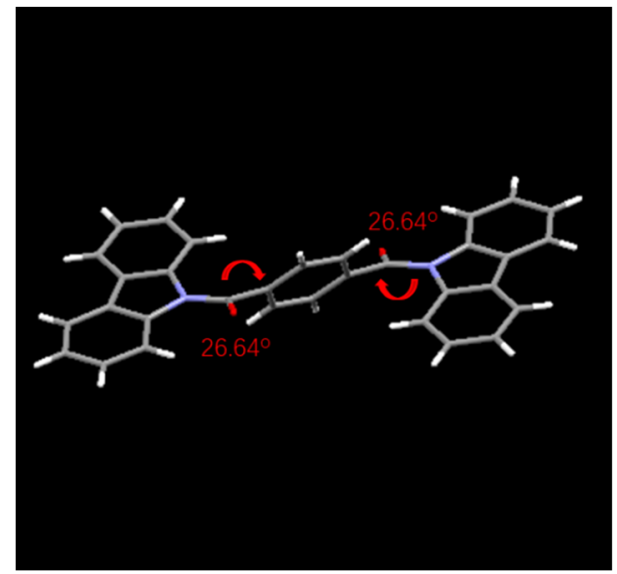

(a)

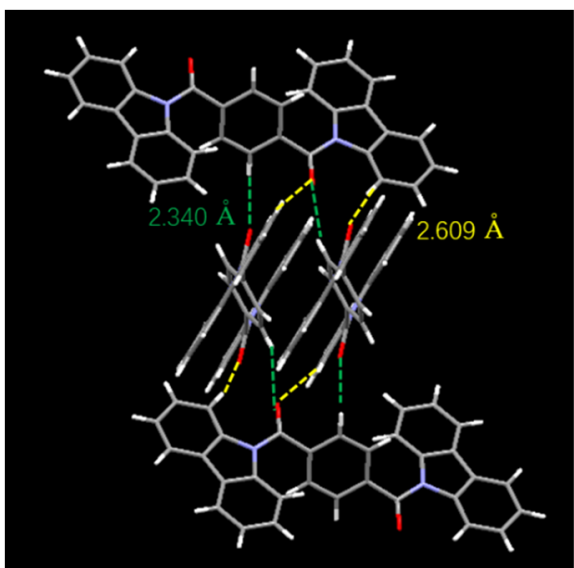

(b)

Figure 6. (a) Dihedral angles in PBCM, as indicated; (b) the unit cell of PBCM and the interactions between molecules.

\subsection{Thermal Properties of PBCM}

The TG and DSC curves of PBCM crystals were measured in the air. Figure 7a shows the DSC curve of PBCM in the second cycle of the heating process. A weak endothermic step was displayed at $105{ }^{\circ} \mathrm{C}$, which might be attributed to the glass transition temperature $\left(\mathrm{T}_{\mathrm{g}}\right)$ resulting from the breaking of the multiple hydrogen bonds between molecules. In addition, a sharp endothermic peak was observed at $280^{\circ} \mathrm{C}$, which corresponds to the melting temperature $\left(\mathrm{T}_{\mathrm{m}}\right)$ of PBCM crystals. Thus, PBCM begins to melt at $251{ }^{\circ} \mathrm{C}$ and completes melting at $287^{\circ} \mathrm{C}$. The TG curve of PBCM, as shown in Figure $7 \mathrm{~b}$, had a small amount of weightlessness below $300{ }^{\circ} \mathrm{C}$. However, with an increase in temperature, it exhibited a rapid weight loss. Nevertheless, PBCM exhibited great thermal stability, 
retaining $90 \%$ of its weight even when heated to $362{ }^{\circ} \mathrm{C}$. Such a high $\mathrm{T}_{\mathrm{m}}$ and good thermal stability of $\mathrm{PBCM}$ are attributed to the strong intermolecular interactions and compact packing structure in crystals.

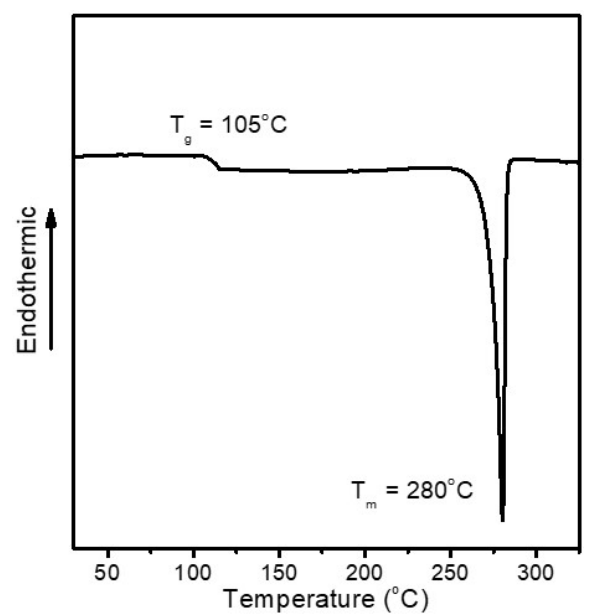

(a)

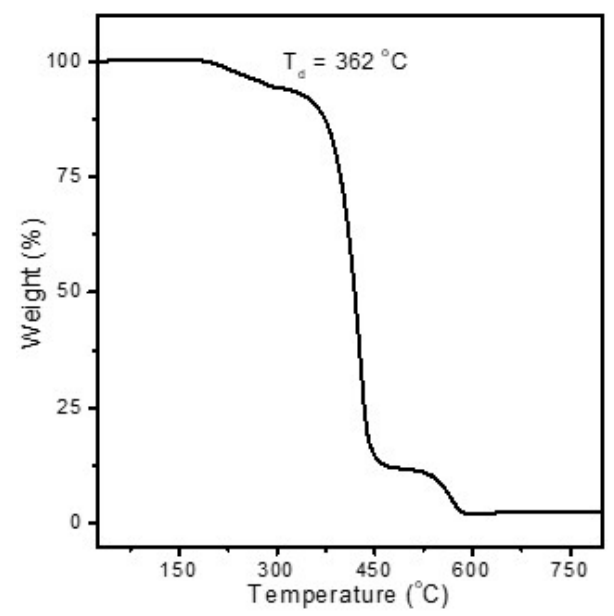

(b)

Figure 7. (a) DSC and (b) TG profiles of PBCM crystals.

\section{Conclusions}

We investigated the PL performances, single-crystal structure, and thermal properties of a D-A-D organic bimodal luminescent material, PBCM. Efficient cyan fluorescence from CT excitons and long-lived yellow RTP from the triplet excited state were both observed in its crystals. The CT effect in the singlet states was found to reduce the $\Delta \mathrm{E}_{\text {st }}$ and promote the ISC processes, resulting in an efficient phosphorescence of $\mathrm{PBCM}$ at room temperature. In addition, the introduction of the D-A-D structure produces many strong intermolecular interactions between the donor and acceptor parts of adjacent molecules, leading to the rigid configurations and compact packing of molecules in crystals, which was also confirmed to facilitate the efficient bimodal emissions of PBCM.

Author Contributions: Formal analysis and investigation, C.Z.; writing-original draft preparation, C.L.; writing-review and editing, J.S.; supervision, M.O. All authors have read and agreed to the published version of the manuscript.

Funding: This work was supported by the National Natural Science Foundation of China (51803056 (J.S.) and 52073257 (M.O.)).

Institutional Review Board Statement: Not applicable.

Informed Consent Statement: Not applicable.

Data Availability Statement: Not applicable.

Conflicts of Interest: The authors declare no conflict of interest.

\section{References}

1. Mei, J.; Leung, N.L.C.; Kwok, R.T.K.; Lam, J.W.Y.; Tang, B.Z. Aggregation-induced emission: Together we shine, united we soar! Chem. Rev. 2015, 115, 11718-11940. [CrossRef] [PubMed]

2. Hirata, S. Recent Advances in Materials with Room-Temperature Phosphorescence: Photophysics for Triplet Exciton Stabilization. Adv. Opt. Mater. 2017, 5, 1700116. [CrossRef]

3. Zhao, J.; Wu, W.; Sun, J.; Guo, S. Triplet photosensitizers: From molecular design to applications. Chem. Soc. Rev. 2013, 42, 5323-5351. [CrossRef] [PubMed]

4. Hong, Y.; Lam, J.W.Y.; Tang, B.Z. Aggregation-induced emission. Chem. Soc. Rev. 2011, 40, 5361-5388. [CrossRef] [PubMed]

5. Braun, D.; Heeger, A.J. Visible light emission from semiconducting polymer diodes. Appl. Phys. Lett. 1991, 58, $1982-1984$. [CrossRef] 
6. Baldo, M.A.; O’Brien, D.F.; You, Y.; Shoustikov, A.; Sibley, S.; Thompson, M.E.; Forrest, S.R. Highly efficient phosphorescent emission from organic electroluminescent devices. Nature 1998, 395, 151-154. [CrossRef]

7. Tong, B.; Mei, Q.; Wang, S.; Fang, Y.; Meng, Y.; Wang, B. Nearly $100 \%$ internal phosphorescence efficiency in a polymer light-emitting diode using a new iridium complex phosphor. J. Mater. Chem. 2008, 18, 1636-1639. [CrossRef]

8. Hoshino, S.; Suzuki, H. Electroluminescence from triplet excited states of benzophenone. Appl. Phys. Lett. 1996, 69, 224-226. [CrossRef]

9. Jankus, V.; Chiang, C.-J.; Dias, F.; Monkman, A.P. Deep Blue Exciplex Organic Light-Emitting Diodes with Enhanced Efficiency; P-type or E-type Triplet Conversion to Singlet Excitons? Adv. Mater. 2012, 25, 1455-1459. [CrossRef] [PubMed]

10. Chaudhuri, D.; Sigmund, E.; Meyer, A.; Rock, L.; Klemm, P.; Lautenschlager, S.; Schmid, A.; Yost, S.R.; Voorhis, T.V.; Bange, S.; et al. Metal-free OLED triplet emitters by side-stepping Kasha's Rule. Angew. Chem. Int. Ed. 2013, 52, 13449-13452. [CrossRef] [PubMed]

11. Marriott, G.; Clegg, R.M.; Arndt-Jovin, D.J.; Jovin, T.M. Time resolved imaging microscopy. Phosphorescence and delayed fluorescence imaging. Biophys. J. 1991, 60, 1374-1387. [CrossRef]

12. Lee, D.R.; Han, S.H.; Lee, J.Y. Metal-free and purely organic phosphorescent light-emitting diodes using phosphorescence harvesting hosts and organic phosphorescent emitters. J. Mater. Chem. C 2019, 7, 11500-11506. [CrossRef]

13. Li, B.; Gong, Y.; Wang, L.; Lin, H.; Li, Q.; Guo, F.; Li, Z.; Peng, Q.; Shuai, Z.; Zhao, L.; et al. Highly efficient organic roomtemperature phosphorescent luminophores through tuning triplet states and spin-orbit coupling with incorporation of a secondary group. J. Phys. Chem. Lett. 2019, 10, 7141-7147. [CrossRef] [PubMed]

14. Zhuo, C.; Ouyang, M.; Li, C.; Zhang, Y.; Cao, F.; Pan, G.; Lv, C.; Zhang, X.; Sun, J. Organic Luminophores Exhibiting Bimodal Emissions of Fluorescence and Room-Temperature Phosphorescence for Versatile Applications. Chem. Sel. 2020, 5, 12770-12776. [CrossRef]

15. Zhao, W.; He, Z.; Lam, J.W.Y.; Peng, Q.; Ma, H.; Shuai, Z.; Bai, G.; Hao, J.; Tang, B.Z. Rational Molecular Design for Achieving Persistent and Efficient Pure Organic Room-Temperature Phosphorescence. Chemistry 2016, 1, 592-602. [CrossRef]

16. Yuan, W.Z.; Shen, X.Y.; Zhao, H.; Lam, J.W.Y.; Tang, L.; Lu, P.; Wang, C.; Liu, Y.; Wang, Z.; Zheng, Q.; et al. Crystallization-Induced Phosphorescence of Pure Organic Luminogens at Room Temperature. J. Phys. Chem. C 2010, 114, 6090-6099. [CrossRef]

17. Scypinski, S.; Love, L.J.C. Room-temperature phosphorescence of polynuclear aromatic hydrocarbons in cyclodextrins. Anal. Chem. 1984, 56, 322-327. [CrossRef]

18. Yuan, J.; Wang, Y.; Li, L.; Wang, S.; Tang, X.; Wang, H.; Li, M.; Zheng, C.; Chen, R. Activating intersystem crossing and aggregation coupling by $\mathrm{CN}$-substitution for efficient organic ultralong room temperature phosphorescence. J. Phys. Chem. C 2020, 124, 10129-10134. [CrossRef]

19. Kuila, S.; Garain, S.; Bandi, S.; George, S.J. All-organic, temporally pure white afterglow in amorphous films using complementary blue and greenish-yellow ultralong room temperature phosphors. Adv. Funct. Mater. 2020, 30, 2003693. [CrossRef]

20. Wei, P.; Zhang, X.; Liu, J.; Shan, G.-G.; Zhang, H.; Qi, J.; Zhao, W.; Sung, H.H.-Y.; Williams, I.D.; Lam, J.W.Y.; et al. New Wine in old bottles: Prolonging room-temperature phosphorescence of crown ethers by supramolecular interactions. Angew. Chem. Int. Ed. 2020, 59, 9293-9298. [CrossRef] [PubMed]

21. Zhang, Z.-Y.; Xu, W.-W.; Xu, W.-S.; Niu, J.; Sun, X.-H.; Liu, Y. A synergistic enhancement strategy for realizing ultralong and efficient room-temperature phosphorescence. Angew. Chem. Int. Ed. 2020, 59, 18748-18754. [CrossRef] [PubMed]

22. Lei, Y.; Dai, W.; Tian, Y.; Yang, J.; Li, P.; Shi, J.; Tong, B.; Cai, Z.; Dong, Y. Revealing insight into long-lived room-temperature phosphorescence of host-guest systems. J. Phys. Chem. Lett. 2019, 10, 6019-6025. [CrossRef]

23. Park, S.K.; Varghese, S.; Kim, J.H.; Yoon, S.-J.; Kwon, O.K.; An, B.-K.; Gierschner, J.; Park, S.Y. Tailor-Made Highly Luminescent and Ambipolar Transporting Organic Mixed Stacked Charge-Transfer Crystals: An Isometric Donor-Acceptor Approach. J. Am. Chem. Soc. 2013, 135, 4757-4764. [CrossRef] [PubMed]

24. Liao, F.; Du, J.; Nie, X.; Wu, Z.; Su, H.; Huang, W.; Wang, T.; Chen, B.; Jiang, J.; Zhang, X.; et al. Modulation of red organic room-temperature phosphorescence in heavy atom-free phosphors. Dye. Pigment. 2021, 193, 109505. [CrossRef]

25. Ouyang, M.; Zhuo, C.; Cao, F.; Pan, G.; Lv, C.; Yang, S.; Li, C.; Zhang, C.; Sun, J.; Zhang, Y. Organogelator based on long alkyl chain attached excimer precursor: Two channels of TICT, highly efficient and switchable luminescence. Dye. Pigment. 2020, 180, 108433. [CrossRef] 